\title{
The Mediterranean Way a model to achieve the 2030 Agenda Sustainable Development Goals (SDGs)
}

\author{
Elvira Tarsitano ${ }^{1}$, Gabriella Calvano ${ }^{1} \&$ Elisabetta Cavalcanti $^{2}$ \\ ${ }^{1}$ Sustainability Center, University of Bari Aldo Moro, Italy \\ ${ }^{2}$ National Institute of Gastroenterology "S. de Bellis” Research Hospital Castellana Grotte Bari, Italy \\ Correspondence: Elvira Tarsitano, Sustainability Center, University of Bari Aldo Moro, Piazza Aldo Moro, Bari, \\ Italy. Tel: 39-080-467-9838. E-mail: elvira.tarsitano@uniba.it
}

$\begin{aligned} & \text { Received: November 6, } 2018 \quad \text { Accepted: December 7, } 2018 \quad \text { Online Published: January } 31,2019 \\ & \text { doi:10.5539/jsd.v12n1p108 }\end{aligned} \quad$ URL: https://doi.org/10.5539/jsd.v12n1p108

\begin{abstract}
The Mediterranean diet, inscribed in the representative list of the intangible cultural heritage of humanity by UNESCO in 2010, is inspired by the traditional food models of Italy, France, Greece, Spain, Portugal, Morocco, Cyprus and Croatia, all countries bordering the Mediterranean Sea. In particular, the Mediterranean area, geographically and territorially, has the characteristics to give value to past food models, which are products of the local territory (legumes, grains, vegetables, fruit, fish). The major aim is to encourage this type of food, which has always been one of the key points for biology studies in the fields of nutrition, food safety and biodiversity protection. The notion of "Mediterranean diet", or "Mediterranean way. How to eat well and stay well" (Keys \& Keys, 1975) does not refer only to a nutritional model shared by many peoples of the Mediterranean basin, but embraces wider and deeper concepts that refer to a peculiar lifestyle, to a specific modality of production and consumption of food, to a certain way of conceiving the relationship between people and the environment. The Mediterranean way is a tool for achieving the goals of the 2030 Agenda for Sustainable Development.
\end{abstract}

Keywords: sustainable development goals, Mediterranean diet, sustainability, biodiversity, good life, well-being, environmental footprints

\section{Introduction}

\subsection{Concepts of Mediterranean Way}

As underlined by UNESCO, the Mediterranean way model goes beyond the simple concept of food, embracing different sustainable values: healthy and nutritional (as it is one of the healthiest eating regimes among those known)(Sofi et al., 2010; 2014), environmental (more limited impact on the environment compared to diets based on an excess of animal fats, respect for the principles of biodiversity, seasonality and frugality, reduction of waste production) (Serra-Majem et al., 2018), quality and food safety (the quality of products and protection of food safety of consumers), social (food awareness, relationship with the territory, conviviality, identity, exchange among people of the Mediterranean area) (Cavaliere et al., 2018), economic (reduction of national health expenditure, savings for consumers, valorization of local companies and territories). As a result, the concepts of Mediterranean way as an unifying reference paradigm for sustainable lifestyles (Tarsitano \& Calvano, 2018).

\subsection{Food Wastes and Its Effects}

In the last hundred years the world population has quadrupled and exponentially has grown a dangerous exploitation of the planet's resources. This has caused the widening of the gap between north and south of the world, between rich and poor. About half of the world's population survives with little choice.

In the eighth report, presented last September $20^{\text {th }}$ in New York, the Global Mpi Report 2018 provides an updated picture on the state of multidimensional poverty in the world, examining 104 countries, about three quarters of the world population (OPHI, 2018). Every year a third of the food produced for human consumption is lost or wasted. These losses occur along the entire supply chain, from farm to fork. In addition to food, there is also a waste of workforce, water, energy, land and other means of production. According to the UN report (UN 2017), the phenomenon of malnutrition has returned to the levels of a decade ago. 821 million people do not have access to 
sufficient quantities of food. In addition, overweight people have risen to 672 million and 821 million of these people suffering from hunger in the world, the majority live in rural areas of developing countries and they are farmers, shepherds or fishermen. They have little access to modern means of preventing food losses and waste and their local food systems are often subject to lack of postharvest practices, transport, processing and refrigeration. The number of malnourished people, due to the low availability of food, is increasing again. In the last three years there has been an increase of $10 \%$ reaching the state in which it was in 2010 . To date, 821 million people suffer from hunger, of whom 151 million are children under the age of 5 years old, that is to say an average of one in nine people. Linked to this aspect of malnutrition is the phenomenon of obesity that spreads mainly in industrialized countries, but which is also spreading in developing countries giving rise to a strongly contradictory coexistence between those who do not receive sufficient nutrients for their own physical development and those suffering from cardiovascular diseases due to overweight. Nowadays, people in obesity are 672 million. These are the data highlighted by the report "The State of Food Security and Nutrition in the World 2018" presented on $11^{\text {th }}$ September 2018 and drafted jointly by major UN agencies, such as the Food and Agriculture Organization of the United Nations (FAO), UNICEF, the World Food Program (WFP), the World health organization (WHO) and the International Fund for Agricultural Development (IFAD) (FAO, 2018).

\subsubsection{Eating Patterns and Biodiversity}

The contemporary world is experiencing a major food emergency. The food we choose to eat, its production chain, the ways and places in which we consume it, and its inequitable distribution in different parts of the planet have a profound effect on the mechanisms that govern our society and our times. In recent years, it has become necessary to compare the different points of view of the actors involved along the food chain, from the field to the table. The link between nutrition and environment is bidirectional. Eating patterns impact the environment, but the environment can also impact dietary choice. Everyday great amounts of food are produced, processed, transported by the food industry and consumed by us and these activities have direct impact on our health and the environment. Food is not just food. It is a concatenation of causes and effects, where food has impact that do not derive only from the agricultural sector, but also from the chemical industry, the production and consumption Therefore, to estimate the environmental impact of a food we consider its life cycle, which examines the entire food supply chain: from the cultivation of raw materials, transport, packaging, production and waste management. These actions have consequences for both human health and the environment (Gussow \& Clancy, 1986; UNEP, 2010).The capacity to produce enough food in the future is limited potentially by water, soil fertility, land use, and stewardship of seas and oceans. Natural resources will be strained and may be lost to future generations if energy, water, and land are not managed and conserved responsibly. Our eating patterns impact the environment, but the environment can impact dietary choices as well. Therefore it is necessary to make responsible food choices to promote personal well being and that, not less important, the environment. To do this, it is essential to follow a sustainable diet. Sustainable eating have low environmental impact, wich contribute to food and nutrition security. In 2012 the Food and Agriculture Organization of the United Nations has defined the sustainable diet as protective and respectful of biodiversity and ecosystems, culturally acceptable, accessible, economically fair and affordable, nutritionally adequate, safe and healthy while optimizing natural and human resources. The food that we produce and consume constitutes $25 \%$ of the environmental impact through greenhouse gas emissions, the use of land and water sources, pollution and the impact of chemical products (herbicides and pesticides) with consequent loss of biodiversity (FAO, 2012). Despite ample literature on environmentally sustainable diets, few studies have considered both dietary patterns and modes of production.

Poore and his colleague Thomas Nemecek (2018) have studied both parameters simultaneously to be able to estimate the extent to which organic food consumption affects diet-related environmental impacts. In particular we assessed the environmental impact categories (GHG emissions, land use, terrestrial acidification, eutrophication, and scarcity-weighted freshwater withdrawals) for 40 agricultural foods from over 38.000 farms. It finds that the environmental impacts of producing the same food are highly variable between different farms and the environmental impacts of animal products are generally higher than plant-based products in particular meat and dairy were the foods that most contributed to environmental footprints. Animal agriculture is the most expensive for the environment (Eshel et al. 2014; Sabaté et al., 2014). More specifically, beef and milk production represent 41 and $20 \%$ of the emissions from livestock, respectively (FAO, 2013). Livestock requires substantial energy for multiple activities such as the production of feed, breeding activities, production and spread of fertilizers, electricity use, and operating costs of farm buildings (FAO, 2003). Intensive livestock production is also responsible for a large part of the loss in biodiversity due to important land use for grass and feed crops. Eshel et al. have demonstrated that ruminant (beef) production requires 28 and 11 times more land and water and emits5 times more GhG, compared with the production of non-ruminant protein sources (e.g. 
chicken, pork, eggs). Several recent studies on the assessment of food related environmental impacts of mean food dietary patterns, generally underline that a shift towards less animal-based and more plant-based diets would have both a beneficial effect on climate and on the environment overall (Baroni et al.,2007).

\subsection{Global Sustainable Development Goals (SDGs)}

In 2015, the Global Community adopted the 17 Global Sustainable Development Goals (SDGs) to improve people's lives by 2030 . The process of changing the development model will be monitored through a complex system based on 17 Objectives, 169 Targets and over 240 indicators. It will be in relation to these parameters that each country will be evaluated periodically by the UN and by national and international public opinions on the state of implementation of the SDGs. The 2030 Agenda represents a major challenge for countries all over the world. In 2016, the UN Statistical Commission approved the global framework for the indicators developed by the Inter-agency and Expert Group about the Sustainable Development Goals (IAEG-SDGs). In July 2018 the "SDG Index and Dashboards Report 2017" was published by the Bertelsmann Foundation and the Sustainable Development Solutions Network (Sdsn), a global study that evaluate the progress of each country according to the SDGs' objectives achieved. The international paper presents the critical points and the strengths of the OECD countries (SDSN, 2017).

The implementation of the Agenda requires a strong involvement of all components of society, from companies to the public sector, from the civil society to philanthropic institutions, from universities and research centers to the information sector and cultural operators.

\subsection{What do We Mean by Mediterranean Way?}

The Mediterranean Diet is a way of life and eating based on the traditional foods of the countries surrounding the Mediterranean Sea. The Mediterranean Diet is not a diet, but is Mediterranean way; it is a lifestyle how to combine personal choices, economic, social and cultural rights, protective of human health and the ecosystem. Eating is an act of precious cultural significance and Mediterranean Way describes a peculiar way of interpreting and experiencing the oldest social act known to mankind: eating which constitutes the synthesis of a set of elements and values of a particular geographical, historical, ethical and cultural area combine economic, social and cultural rights, protective of human health and the ecosystem: the Mediterranean basin. The term Mediterranean Way expresses a relationship between man and food in which the challenge lies, therefore, in finding the correct mode of reconciling the "Mediterranean Way" and contemporary lifestyles through identifying the economic and social and individual choices which also make it possible to preserve "Mediterranean" values in the future social-economic and environmental context. Therefore, dietary patterns can substantially vary in resource consumption and the subsequent impact on the environment, as well as on the health of a given population. In literature it's highlighted that the MD has significant health-nutrition benefits and low environmental footprints (Dernini \& Berry, 2015; Aboussaleh et al., 2017), due to principally the consumption of more plant-derived products and less animal products ; in particular vegetables and fruits are the most important source of fibers and chemical compounds, likeflavonoids, phytosterols, vitamins, terpenes and phenols, which give protection against oxidative processes, hence reducing the incidence of metabolic and cardiovascular diseases (Del Chierico et al. 2014). For these reasons, the Mediterranean diet and, more generally, the Mediterranean Way fall within the FAO definition of sustainable diets that are "diets with low environmental impacts which contribute to food and nutrition security and to healthy life for present and future generations. Sustainable diets are protective and respectful of biodiversity and ecosystems, culturally acceptable, accessible, economically fair and affordable; nutritionally adequate, safe and healthy; while optimizing natural and human resources" (FAO, 2010).

Actually, the adherence to the Mediterranean diet model is decreasing due to the change of several factors such as the life styles changes, food globalization, environmental changes and economic, socio-cultural factor. These changes threaten life and the preservation and transmission of the Mediterranean diet heritage to present and future generations. Thus, must be necessary to move from current food models to more environmentally and healthily conscious habits in all European countries by adhering to Mediterranean Way.

\subsection{Objective}

Inspired by this sustainable, holistic and systemic notion of the Mediterranean diet, better the Mediterranean way as lifestyle (modus vivendi), the Sustainability Center of the University of Bari (Italy), identifies the importance in education about the sustainable food culture, the scientific research, training and creation of wide and comprehensive partnership networks. In addition to many instruments for the defense of human rights, such as the right to an adequate and sufficient nutrition for everyone, a healthy and good life, an intact and healthy environment, as well as the respect for and enjoyment of common goods and specific cultural identities and 
biodiversity of the territories, including the food production according to principles of sustainability, dignity and equity for all the people involved. It is necessary a planning for an active Ecological citizenship by developing projects as the creation of a permanent Laboratory for Ecological Sustainability and Socio-Economic Anthropic Development.

\section{Method}

\subsection{Integrated and Participatory Planning Approach}

Integrated-Participatory Planning (IPP) is the most modern instrument available for planning and organizing human activities in urban areas: these are both urban and extra-urban (Tarsitano, 2006).

Cities are true 'organisms' and as such they form part of a more complex system, the surrounding or catchment area. As organisms, cities can be studied from a methodological point of view in terms of their growth mechanisms, their transformation and their decline by making use of an innovative approach as a discipline. The principles of the development and growth of an ecosystem can be applied to planning, i.e., the principles can be applied to the establishment of a rational regional planning policy. Cities are high energy-consumption systems which impact on nature in order to maintain their balance. That is why it is important to preserve the 'natural capital', so as to be able to guarantee the necessary input of natural resources without running the risk of incurring a dangerous decline in the quality of life: cities must be tailored to their inhabitants. Nature must be preserved within a circumscribed administrative unit (city, region, state) in order to ensure and maintain a suitable level of development of human society. Indeed, nature itself is a system which in and of itself can protect and maintain life, can stabilize substrates, maintain balance in air and water cycles, moderate extremes of temperature and other physical factors, and so on. It follows that the basis for planning must be the ability for life to maintain itself. The aim of integrated-participatory planning is to understand and protect the natural environment which is so vital to the maintenance of life; to protect the quality of life in cities; to regulate insofar as this is possible - the type and pace of development in order to ensure that it does not exceed the carrying capacity of nature and to ensure that pressures on the environment be kept to a minimum; to exploit nature less and more efficiently and to recycle more. An ecological understanding of an area means reestablishing and guaranteeing harmony between urban settlements and the surrounding extra-urban territory. Appropriate strategies must be chosen to combat environmental deterioration, by planning and applying rules governing human settlements both inside cities and outside them which will themselves generate a new and lasting environmental equilibrium (Figure 1) (Tarsitano, 2006).

\subsection{Sustainable Plans and Ecological Balance Sheets}

Eco-plan method use theme maps as cognitive instruments and guidance instruments; assessments are carried out and sustainable planning solutions are found (Sachs, 2004) (eco-management). Ecological Balance Sheets (EBS) are an important instrument for recording all the significant impacts of anthropic activities on the environment (Greenland et al,., 2003). Urban sustainability indicators (Sachs, 2004; Wackernagel \& Rees, 1996) can become very useful analytical and evaluative tools for the assessment of actions and strategies adopted in cities. The indicators can also be used as guidance tools to adjust sustainable city planning policies to foster quality of life, public health and environmental health (McCool \& Stankey, 2004; Hancock, 2002; Cole et al.,1998). Using an ecological balance sheet is of great benefit in understanding the state of health of the environment and in achieving a better grasp of the pressures of human activities on a specific area, not to mention its usefulness in terms of protecting the environment and in terms of helping the environment recover when responding to environmental, health and social problems (Sachs, 2004; de Neufville, 1986).

Another useful tool is the indicators for sustainable development published recently by ASviS (2018) with an online document entitled "Monitoring the SDGs at EU level with composite indicators". A unique set of composite indicators that summarize almost 70 elementary indicators, able to measuring progress and backward steps made by the $28 \mathrm{EU}$ member states compared to the SDGs. For the first time at international level, a set of indicators summarizes the position of each of the $28 \mathrm{EU}$ member states in the perspecrive of the achievment of the UN Sustainable Development Goals. Given the complexity in verifying the implementation status of the 2030 Agenda, composite indicators are not intended to be a simplification of the problem, but a tool that allows a quick and concise view of the performance related to each Objective. The indicators were constructed using the Ampi methodology, also adopted by Istat for composite indicators of Fair and Sustainable Well-being (Bes) (https://www4.istat.it/it/benessere-e-sostenibilit\%C3\%A0/misure-del-benessere). 


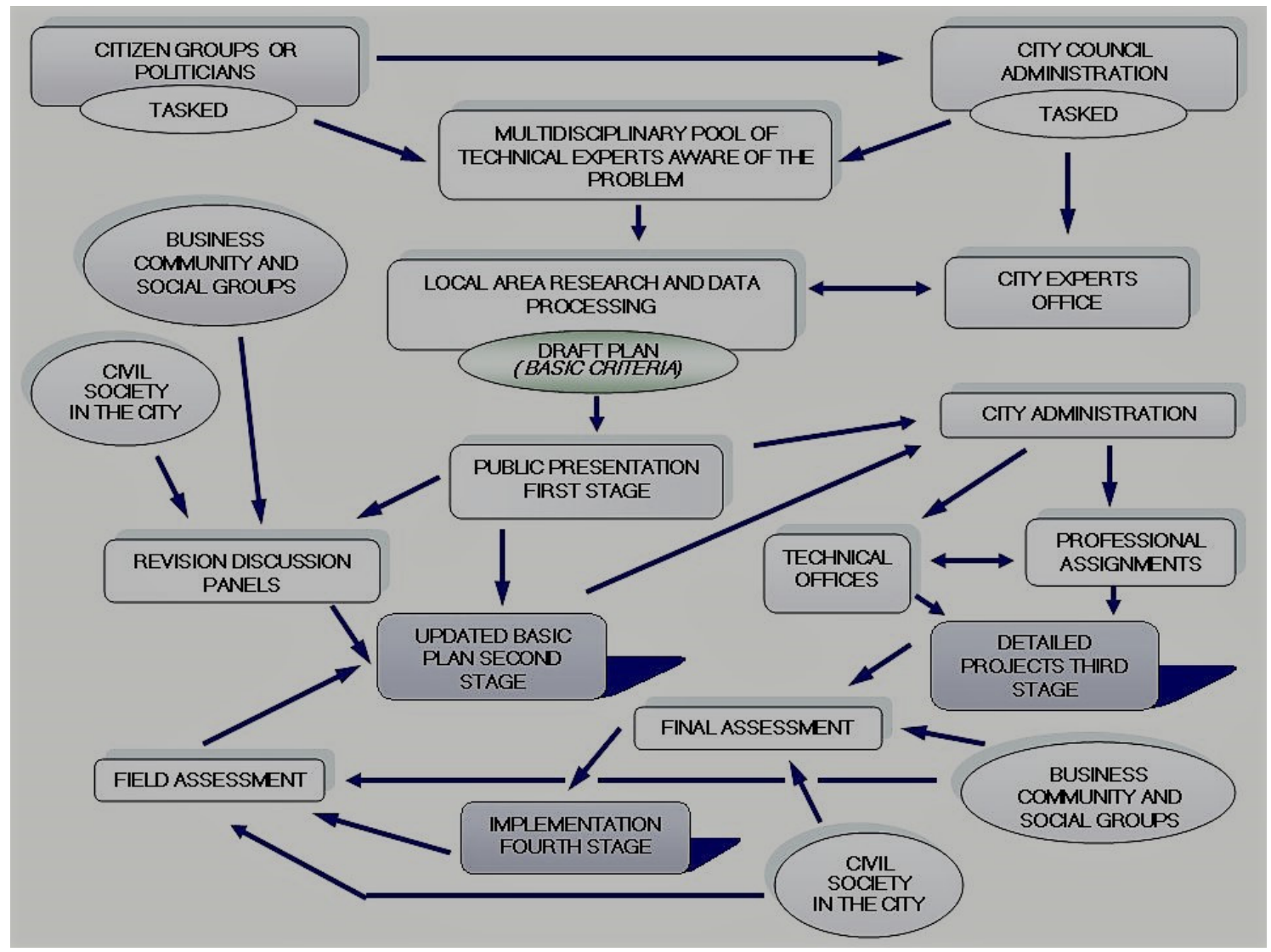

Figure 1. Historical path of Integrated-Participatory Planning (IPP)

\section{Discussion}

\subsection{Poverty Alleviation, Economic and Social Rural Development}

The living present must concern us for several reasons: for the dramatic lack of homogeneity in the distribution of resources and their uses; for the absence of any idea of equalization and the dramatic approach of the limit in the consumption of many planetary resources; achieved load capacity for different ecosystems. The most «developed» countries must absolutely reduce their impact on the biosphere, modifying their lifestyles, in a reasonable and reasoned way, to allow other countries simply to survive.

Any strategy in the sociological and economic field that aims to fight poverty and social exclusion cannot ignore the fact that the environment in which we live, invites us to look for new answers, not only technological, as well as to answer to collective needs and not only to individual needs.

In fact, from the data published in the Multidimensional poverty index: $80 \%$ of the poor are concentrated in Sub-Saharan Africa and South Asia, while about 50\% are children and teenagers.

The figures for other regions are less severe. From 19\%, as in the Arab States, to 2\% in Europe and Central Asia. Then, there are considerable disparities within the same countries; Despite the poverty, in its multidimensionality, is still widespread there are signs of improvement. The poverty can be defeated but timely action is required. In addition to the 1.3 billion classified as poor, there are another 879 million people to be considered at risk. A risk that may not be so far away if we do not intervene promptly to solve problems such as conflicts, droughts and unemployment. The UNP recommends immediate action (OPHI, 2018).

The UN could soon launch a global environmental compact. A new, broader and more binding agreement, which will work in parallel with that of Paris and which must be able to restore environmental failures. During a meeting of the United Nations last September, the President of the General Assembly launched the idea of a Global Compact for the environment. A compact that could materialize after the UN has worked out about the most important environmental problems and failures (UN, 2018). To address these issues, the Global Commission on the Economy and Climate, which aims to help governments, businesses and companies make more informed 
decisions on how to achieve economic prosperity and development, addressing the challenges of climate change, has developed the 2018 report "Accelerating climate action in urgent times" identifying five key economic systems: energy, city, food and land use, water and industry that are key sectors for the economy of the future. But the challenge is greater than we can imagine: the climate as a driver of social inclusion. Actually, more efficient and interconnected cities could reduce infrastructure capital requirements by more than three trillion dollars up to 2030. Agriculture and forests can become another important factor by offering greater food security, nutritious food, greater prosperity, rural resilience and valuable ecosystem services, including water management, soil fertility and carbon sequestration. Furthermore, reawakening the potential of the circular economy can radically reduce the demand for energy-intensive raw materials, increasing material productivity and reducing wastes. The transition to a low-carbon and resilient economy is only a part a broader transformation that can manage its potential to offer more equitable and prosperous social growth. In conclusion, the goal of this new growth approach is to ensure greater productivity, more resilient economies but above all social inclusion. The poor people are those most exposed to the impacts of global warming, and a new climate economy could not only benefit the environment, but also rebalance the injustices of our society (Global Commission on the Economy and Climate, 2018).

"It would seem a utopia but it is the only 'sustainable' possibility. The alternative would be a profound environmental, economic and social crisis of the whole world" (Giovannini, 2018). All of this must necessarily be accompanied by a lifestyle that respects sustainability and the Mediterranean diet, a model of sustainable diet, is an example of how to combine personal choices, economic, social and cultural rights, protective of human health and the ecosystem.

\subsection{Agriculture and Ecology. A Link to Rebuild}

Until the beginning of the last century the farmers have been the protagonists of change and innovation in agriculture, the result of collective work done in the family and in the community. We can attribute to agriculture not only the importance of its nutritional functions, but it has always had an important role to face problems through innovative solutions which have been also pass down from generation to generation, together with the land, the biodiversity and its acquired knowledge: soil fertilization, seed improvement techniques, irrigation, good agricultural practices, farm equipments and animal breeding. This task of these innovative farmers has been possible thanks to the multiplicity of their knowledge, or as we would say today an "interdisciplinary" approach. In addition to being agricultural producers, they were real ecologists. They knew geography: climate and topography; botany: plants, flowers and fruits; zoology and entomology: animals and insects; physics: soil, minerals and waters. In the '50s all this has suffered a drastic arrest and we have witnessed throughout Europe to the development of industrialized agriculture, dissociated from the local social and economic reality of peasant societies and independent of environmental and social conditions in which life really evolves. The result was a type of agriculture that has put in crisis the innovations and knowledge that came from the farmers, where the chemistry was marginal, the best seeds were propagated, the crossings that came from positive mutations were used, together with working techniques, irrigation and fertilization work experience used for years and years: the polycultural practices that sealed the alliance between man and nature.

By reducing losses and waste across the entire supply chain, healthy food systems can help to promote climate adaptation and mitigation, preserving natural resources and strengthening rural livelihoods.

Another agriculture is possible. By combining tradition and innovation through the multi-functionality and diversification of agriculture such as the quality of products, rather than the only production, reproducibility of resources, protection and valorization of the landscape, cultural values and ethical ones in a perspective of sustainability (Tarsitano \& Calvano, 2018) as occurs in the Mediterranean diet/way. Within the EU framework for rural development programs, the Member States and regions develop their rural development programs according to the needs of their territories and taking into account at least four of the following six common EU priorities: promoting the transfer of knowledge and innovation in agriculture, forestry and rural areas; enhance the profitability and competitiveness of all types of agriculture and promote innovative technologies for farms and sustainable forest management; fostering the organization of the food supply chain, animal welfare and risk management in the agricultural sector; encouraging, restoring and enhancing ecosystems related to agriculture and forests; supporting the efficient use of resources and the transition to a low carbon and climate resilient economy in the agri-food and forestry sector; promote social inclusion, poverty reduction and economic development in rural areas.

To be able to conjugate the "tradition" with the "technology" is a challenge of our millennium for the benefit of quality and sustainability of good life and well-being (Tarsitano \& Calvano, 2018) (Table 1) and the 
Mediterranean diet/way adapts easily to changes by improving its current perception not only as a healthy diet but also a sustainable lifestyle.

Table 1. How to achieve the Sustainable Development Goals (SDG) in the Mediterranean area

\begin{tabular}{l}
\hline The way forward \\
\hline Sustainable farming systems under environmental and climatic constraints \\
Water resources and Fisheries Management \\
Food value chain for regional and local development \\
Reducing food waste and enhancing by-product innovations \\
Nutrition and Education \\
Sustainable tourism
\end{tabular}

In the book "Agriculture and climate change" Fritjof Capra (2017), explains how agroecology, which includes systems such as organic farming, biodynamic and permaculture, has proven to be more resistant to global warming than industrial agriculture and able to help stabilize the world's climate. According to the author, there is a twofold link between industrial agriculture and climate change: the agricultural system based on monocultures and chemistry has proved to be more vulnerable to extreme weather events, contributing, in turn, to greenhouse gas emissions due to the use of to fossil fuels and large amounts of energy.

The real and progressive increase of the environmental, climate, food and health crisis of our century, requires to reconstruct the connections between geography, chemistry, botany, zoology, climatology and evolutionary history of civilization belonged to western farmers in the last century. This is a fragmented evolutionary process owned by those in the South of the world, even if it finds still obstacles in the practice of industrial agriculture models, despite the established and overt failure (Tarsitano \& Calvano, 2018).

Recovering the dimension and the perspective of the community network, places man in front of the necessity of an "integrated approach to fight poverty, to restore dignity to the excluded and at the same time to take care of nature" (Francesco, 2015). We are facing a new conceptual paradigm that Pope Francis calls Integral Ecology (Id., IV, § 137), a paradigm that "integrates the specific place that the human being occupies in this world and his relations with the life that surrounds him" (Id., § 15). Integral Ecology consists of four models of ecology (environmental, human, economic and cultural) linked together by a close relationship of interdependence whose sole purpose is to empower and lead man to the common good.

\subsection{Synergies for Health, Environment and Economy}

Agriculture must return to open itself towards other knowledge, like new connections between air and water, earth and living organisms (plants and animals), because they represent the real foundation of ecological knowledge.

Worth mentioning is that the act of eating, more than any other experience, puts man in relationship with the natural world. Feeding together is a necessity and the most direct and complete way to relate to the world outside us, to express our culture through the choice of food and the methods of consumption. The state of health is a condition of complete physical, mental, sexual, spiritual and relational well-being together with the biotope and the biocoenosis of one's own niche. Well-being is that harmony between man and nature.

So the richness of food species is fundamental to our well-being. The demand for food from biodynamic and organic agriculture is increasingly (Tarsitano \& Calvano, 2018).

At the same time the nutritional value of many of the more traditional foods have changed (Marles, 2017). This can happen when there are new varieties or new sources of supply for raw materials; with new farming practices which can affect the nutritional value of both plant and animal products. Dwindling of natural and food resources has led to a biodiversity decline. Losing biodiversity means loss of diet quality, which can lead to micronutrient deficiencies, food insecurity, more pests on farms, fragile ecosystems, and the loss of culture and tradition. Thus, biodiversity should not only be recognized as an important player in sustainable agriculture, but also as a necessary contributor to a healthy diet (Fanzo et al., 2013).

Therefore, there is a need to understand the relation between sustainable diets and the health of a population. In recent years, a number of studies have investigated and compared different dietary patterns to better understand 
which foods and eating patterns have less environmental impact while meeting nutritional needs and promoting health. In recent years, governmental dietary recommendations from various countries have begun to integrate sustainability. According to a recent report by the Food and Agriculture Organization (Fischer et al, 2016), of 83 countries that have official dietary guidelines, there are 4 reported countries (Sweden, Germany, Brazil, and Qatar) that are beginning to integrate sustainability into their dietary guidelines and are calling on consumers to eat less animals and more plant-based foods.

The Mediterranean diet model in many studies has been appreciated to have a lower environmental impact, mainly due to its consumption of more plant-derived products and less animal products, with respect to other current dietary patterns (Tilman \& Clark, 2014). It is not by chance that at the end of 2010, the Mediterranean diet was inscribed in the UNESCO Representative List of the Intangible Cultural Heritage of Humanity.

Therefore, the Mediterranean way model was considered as an unifying reference paradigm for healthy lifestyles and it should be extended to all European countries. The assessment of the sustainability of the Mediterranean diet in different countries requires also to evaluate direct and indirect interactions and correlations, between nutrition/health and environmental indicators, together with indicators related to the socio-cultural and economic dimensions of sustainability. Because all current adherence scores refer only to the nutritional and health benefits of the traditional Mediterranean diet model (Sofi et al., 2014), there is also a need to develop and validate new comprehensive adherence scores for the Mediterranean diet model as a sustainable dietary pattern for the contemporary times. Food plays a central role in the social and cultural life of the Mediterranean area.

In this context, investigations in the early 90 s already showed that dietary patterns throughout the Mediterranean countries were increasingly moving away from those reported in the $60 \mathrm{~s}$.

Moreover, more recent data have confirmed that in many Mediterranean countries the loss of adherence to the Mediterranean diet is continuing and increasing (Garcia-Closas et al., 2006), linked also to the current economic downturn (Bonaccio et al., 2014). A focus on the model of the Mediterranean way as a sustainable food model would be beneficial for its revitalization.

Therefore, more cross-cutting studies through the nutritional/ health, environmental, economic and socio-cultural dimensions of the Mediterranean way must be necessary to drive from current food models to more environmentally friendly habits in all European countries and beyond.

\section{Conclusion}

\subsection{The Resilience Strategy}

To return to the ecological capabilities, the way is that of structurally reduce the systemic food wastes, at least from a third of the current in the world, to a quarter in Italy. It is necessary to recognize that the food is a common good, with greater social and economic value, fair production and access, avoiding commercial and wasteful excesses. Overall demands and consumer surpluses must be reduced, production must be made environmentally friendly and self-sufficient, reversing the agricultural/natural soil consumption, supporting alternative food networks, by putting together resilient communities, reducing animal products, unhealthy fats, salts, sugars, links with financial systems and international trade, thanks to a kind of a circular bioeconomy that avoids the so-called paradox of Jevons (simultaneous increases in efficiency and total resources consumed) (Vulcano \& Ciccarese, 2017). The key word becomes "resilience", that is to say "the ability to react "; if a shocking future awaits us. Resilience, however, is not to be considered only the ability to go back to the initial position especially because, explains the ASviS' spokesman, returning to where we were before a shock makes sense only if we were on the right way. On the contrary, the concept is to bounce forward not to bounce back. If the shock is of great extent and lasts a long time, we must transform ourselves. Then, these policies of protection, promotion, preparation, prevention, by cross cutting the economic, social and political categories can allow us to change those interests in a different way from the past (Giovannini, 2018).

\subsection{Mediterranean Biodiversity towards Sustainable and Resilient Communities: Successful Case Studies in the Mediterranean Area}

A success story: The community cooperatives. The Community cooperatives are the only instrument able to put people at the center of their objectives and making them protagonists of change, because these are based on listening to their "needs". There is no story alone. There are communities that because the same needs have decided to work together and put in place common actions that then become a benefit for everyone. The development model of the Community Cooperatives is that of a shared management of the common good, on which Legacoop has decided to launch its challenge. Legacoop is an association that for over 125 years brings together over 15 thousand cooperatives, it acts in all Italian regions and in all sectors to create development, by 
putting people and territory at the center of their projects. In order to achieve its objectives, the association develops services and projects for cooperative enterprises and promotes cooperative culture, affirming its values and supporting its economic, social and civil role and able to respond to people needs. It is one of the most modern model of active citizenship, which sees groups of people, based on specific needs, self-organized and engaged in actions to promote and enhance the territories, together with the production of goods and services. It can constitute a starting point in order to create resilient and sustainable cooperatives (Legacoop, 2010).

In June 2017 the Mayors of the Italian metropolitan cities signed the environmental "Bologna Charta", created with the contribution of the Italian Alliance for Sustainable Development (ASviS), containing concrete commitments on the themes of Sustainable Development. In March 2018 the ASviS and the National Center for Studies on Urban Policies (Urban @ it) released the final version of the Urban Agenda for Sustainable Development, a document elaborated with a complex procedure of consultations and full of proposals for " make cities and human settlements inclusive, safe, resilient and sustainable ", as foreseen by the Objective 11 of the UN 2030 Agenda. This commitment to the construction of the Urban Agenda for sustainable development has been accepted by the Italian University Network for Sustainable Development (RUS) which is a network of Italian universities that aims to disseminate research and good practices of sustainable development among teachers, students, university staff and citizens. The RUS will work together with ASviS and within the most important Metropolitan Cities to pursue the Goal 11 of the Agenda 2030 and build sustainable and resilient cities. The challenge of the future is in the cities. This was also underlined by the ASviS Report 2018, a report that measures the positioning of Italy according to the Sustainable Development Goals (ASviS, 2018). Through a series of indicators it emerged that renewed policies are needed that put the city at the center of the political agenda, because it represents a challenge for climate change, mobility, migratory processes and for the relationship with the surrounding rural areas. The attention to the city is today particularly important for the increase in the percentage of the world population that lives in the city and no longer in the rural areas. This will also have repercussions on food policies that represent a new challenge for urban planning (FAO, 2018). The New Urban Agenda (UN, 2017), in fact, has highlighted how local governments will have to put food and good food at the center of their policies if they want to achieve the Goals of the Agenda 2030.

The results of the ASviS' project "Monitoring the SDGs at EU level with composite indicators", provide to all parties concerned and the media too, concise, clear and easy to read assessments of the progress made by the EU and individual countries compared to each Objective. Thanks to this work, each Member State will be able to further develop its composite indicators using additional elementary indicators. The analysis carried out shows signs of improvement compared to 2010 for eight out of 15 indicators: health, education, gender equality, energy system, innovation, urban conditions, sustainable models of production and consumption, fight against climate change. For two indicators the situation continue to worsens significantly (inequalities and terrestrial ecosystem), while for five (poverty, food and sustainable agriculture, economic and employment status, quality of governance and international cooperation) the situation appears substantially unchanged.

It is necessary a renewed planning that puts an active eco-citizenship as its main objective. Everyone, in particular the world of education, universities and research centers, but also politicians too are called to play their part, developing projects that go in this direction as the "Creation of a permanent Laboratory for Ecological and Socio Economic Sustainability of Anthropic Development for Social Inclusion ".

Raised to live our environment as an essential component of our life and educated to the sense of belonging, the citizens who participate in collective life develop skills, culture, interests and mental flexibility and become in turn the resource and heritage of their cities and communities.

If we succeed, also through the commitment of an active and reflective eco-citizenship, to reduce the environmental impact of our daily activities and to reduce consumption, we will be able to allow all the inhabitants of our planet to live and, not only, to try to survive.

It is about knowing, recognizing and appreciating the ancient flavors of our agri-food tradition, and trying to safeguard our different ecosystems throughout the Mediterranean area. The local product is linked to the land where it is produced, to its environmental resources, to its historical processes, to its community networks and people who live there. Healthy eating is the most direct and complete way to relate to the surrounding world, to express our culture through the choice of food and the methods of consumption. It must be taken into account that the state of health of people, their equilibrium and their psycho-physical well-being, are closely linked to the relationship with the environment in which they live and to interactions with others, including animals and plants, waters, smells and flavors: it would be like eradicating people from their natural history, turning away from him those ancestral experiences that linked us to the mother earth and that have shaped tastes and choices, including 
food. The distinctive character must be that of a sustainable, holistic, systemic and biocentric approach to healthy eating: we believe that lifestyle modifications and individual behavior can lead us on the path of awareness for the improvement of quality and sustainability of life.

In conclusion, the Mediterranean way is a tool for achieving the goals of the 2030 Agenda for Sustainable Development.

\section{References}

Aboussaleh, Y., Capone, R., \& Bilali, H.E. (2017). Mediterranean food consumption patterns: low environmental impacts and significant health-nutrition benefits. Proc Nutr Soc. Nov, 76(4), 543-548.

AsviS. (2018). L'Italia e gli Obiettivi di Sviluppo Sostenibile. Rapporto ASviS 2018. Rome. Retrieved from http://asvis.it/public/asvis/files/ASviS_REPORT_2018_web_last.pdf

AsviS. (2018). Monitoring the SDGs at EU level with composite indicators. Retrieved from http://asvis.it/public/asvis/files/ASVIS-REPORT-EU-COMPOSITES-FINAL.pdf

Baroni, L., Cenci, L., Tettamanti, M., \& Berati, M. (2007). Evaluating the environmental impact of various dietary patterns combined with different food production systems. Eur J Clin Nutr, 61, 279-286. https://doi.org/10.1038/sj.ejcn.1602522

Bonaccio, M., Di Castelnuovo, A., Bonanni, A., Costanzo, S., De Lucia, F., Persichillo, M., ... Iacoviello, L. (2014). Decline of the Mediterranean diet at a time of economic crisis. Results from the Molisani study. Nutr Metab Cardiovasc Dis, 24(8), 853-60. https://doi.org/10.1016/j.numecd.2014.02.014

Cadenasso, M. L. (1999). Baltimore long-term ecological research program: Ecology of the city. Bard College, Annandale-on-the-Hudson, New York. July 21, 1999.

Capra, F., \& Lappé, A. (2017). Agricoltura e cambiamento climatico, Aboca, Arezzo.

Cavaliere, A., De Marchi, E., \& Banterle, A. (2018). Exploring the Adherence to the Mediterranean Diet and Its Relationship with Individual Lifestyle: The Role of Healthy Behaviors, Pro-Environmental Behaviors, Income, and Education. Nutrients, 28, 10(2).

Chambers, N., Simmons, C., \& Wackernagel, M. (2000). Sharing Nature's Interest: Ecological Footprints as an Indicator for Sustainability. Earthscan, London.

Cole, D. C., Eyles, J., \& Gibson, B. L. (1998). Indicators of human health in ecosystems: what do we measure? Science of the Total Environment, 224, 201-213. https://doi.org/10.1016/S0048-9697(98)00350-7

de Neufville, J. I. (1986). Usable planning theory: An agenda for research and education. In B. Checkoway (Ed.), Strategic perspectives on planning practice (pp. 43-59). Lexington, Lexington Books.

Del Chierico, F., Vernocchi, P., Dallapiccola, B., \& Putignani, L. (2014). Mediterranean diet and health: food effects on gut microbiota and disease control. Int $J$ Mol Sci., 15(7), 11678-99. https://doi.org/10.3390/ijms150711678

Dernini, S., \& Berry, E. M. (2015). Mediterranean Diet: From a Healthy Diet to a Sustainable Dietary Pattern. Front Nutr., 2(15).

Eshel, G., Shepon, A., Makov, T., \& Milo, R. (2014). Land, irrigation water, greenhouse gas, and reactive nitrogen burdens of meat, eggs, and dairy production in the United States. Proc. Natl. Acad. Sci. USA, 111, 11996-12001. https://doi.org/10.1073/pnas.1402183111

Fanzo, J., Hünter, D., Borelli, T., \& Mattei, F. (2013). Diversifying Food and Diets: Using Agricultural Biodiversity to Improve Nutrition and Health (Issues in Agricultural Biodiversity). Routledge, Halewood UK. https://doi.org/10.4324/9780203127261

FAO, IFAD, UNICEF, WFP and WHO. (2018). The State of Food Security and Nutrition in the World 2018. Building climate resilience for food security and nutrition. Rome. Retrieved from http://www.fao.org/3/I9553EN/i9553en.pdf

FAO. (2003). World Agriculture: towards 2015/2030. An FAO Perspective. Rome. Retrieved from http://www.fao.org/3/a-y4252e.pdf

FAO. (2010). Sustainable diets and biodiversity. Directions and solutions for policy, research and action. Proceedings of the international scientific symposium: biodiversity and sustainable diets: united against hunger, 3-5 November 2010. Food and Agriculture Organization of the United Nations (FAO), Rome, Italy. Retrieved from http://www.fao.org/docrep/016/i3004e/i3004e.pdf 
FAO. (2012). Sustainable Diets and Biodiversity Directions and Solutions for Policy, Research and Action. Rome. Retrieved from http://www.fao.org/docrep/016/i3004e/i3004e.pdf

FAO. (2013). Tackling Climate Change Through Livestock. A Global Assessment of Emissions and Mitigation Opportunities. Rome. Retrieved from http://www.fao.org/3/a-i3437e.pdf

FAO. (2018). Integrated Food into Urban Planning. UCL Press: London. Retrieved from http://discovery.ucl.ac.uk/10061454/1/Integrating-Food-into-Urban-Planning.pdf

Fischer, C. G., \& Garnett, T. (2016). Plates, Pyramids and Planets Developments in National Healthy and Sustainable Dietary Guidelines: A State of Plays Assessment. Oxford, UK. Retrieved from http://www.fao.org/3/a-i5640e.pdf

Foresman, T. W., Pickett, S. T. A., \& Kuhlman, K. (1999). Link globally, act locally: Baltimore ecosystem study. GeoInfoSystems, 9, 24-29.

Francesco. I. (2015). Laudato Si. Encyclical Letter of the Holy Father on care of our Common Home. Vatican City. Retrieved from http://w2.vatican.va/content/francesco/en/encyclicals/documents/papa-francesco_20150524_enciclica-lauda to-si.html

Garcia-Closas, R., Berenguer, A., \& González, C. A. (2006). Changes in food supply in Mediterranean countries from 1961 to 2001. Public Health Nutr., 9(1), 53-60. https://doi.org/10.1079/PHN2005757

Giovannini, E. (2018). L'Utopia Sostenibile. Laterza, Rome.

Global Commission on the Economy and Climate. (2018). Unlocking the Inclusive Growth Story for the $21^{\text {st }}$ Century: Accelerating Climate Action in Urgent Times. Washington DC. Retrieved from https://newclimateeconomy.report/2018/wp-content/uploads/sites/6/2018/09/NCE_2018_FULL-REPORT.p df

Greenland, D., Goodin, D., \& Smith, R. C. (2003). Climate Variability and Ecosystem Response at Long-Term Ecological Research Sites. Oxford University Press.

Gussow, J. D., \& Clancy, K. L. (1986). Dietary guidelines for sustainability. J Nutr Educ, 18, 1-5. https://doi.org/10.1016/S0022-3182(86)80255-2

Hancock, T. (2002). Indicators of environmental health in the urban setting. Canadian Journal of Public Health, 93, 45-51.

Jardine, C., Hrudey, S., Shortreed, J., Craig, L., Krewski, D., Furgal, C., \& McColl, S. (2003). Risk management frameworks for human health and environmental risks. Journal of Toxicolology and Environmental Health Part B Critical Reviews, 6(6), 569-720. https://doi.org/10.1080/10937400390208608

Keys, A., \& Keys, M. (1975). Eat well and stay well, the Mediterranean way. Doubleday.

Legacoop. (2010). Il progetto Cooperative di Comunità. Rome. Retrieved from http://www.legacoop.coop/cooperativedicomunita/il-progetto-legacoop/

Marles, R. J. (2017). Mineral nutrient composition of vegetables, fruits and grains: The context of reports of apparent historical declines. Journal of Food Composition and Analysis, 56, 93-103. https://doi.org/10.1016/j.jfca.2016.11.012

McCool, S. F., \& Stankey, G. H. (2004). Indicators of Sustainability: Challenges and Opportunities at the Interface of Science and Policy. Environmental Management, 33, 294-305. https://doi.org/10.1007/s00267-003-0084-4

Meadows, D., Rothenberg, J., Sinai, A., Wilson, E. O., \& Myers, N. (1992). Biology and the balance sheet. Earthwatch, 6-9.

Nancy, B., Grove J. M., Pickett, S. T. A., \& Redman, C. L. (2000). Integrated approach to Long-Term studies of

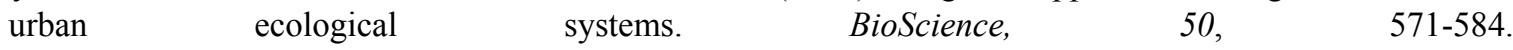
https://doi.org/10.1641/0006-3568(2000)050[0571:IATLTO]2.0.CO;2

Oleskòw, J., Golinska, P., \& Stachow F. (2003). The Eco balance sheet algorithm. Proceedings of the Formal Methods and data Processing Techniques, ITEE 2003, 24-26 June 2003, Edmonton, Alberta.

OPHI. (2018). The Global Multidimensional Poverty Index Report: The Most Detailed Picture to Date of the World's Poorest People. Oxford. Retrieved from http://www.indiaenvironmentportal.org.in/files/file/global_MPI_Report-2018.pdf 
Poore, J., \& Nemecek,T. (2018) Reducing food's environmental impacts through producers and consumers. Science, 1;360(6392), 987-992.

Sabaté, J., Sranacharoenpong, K., Harwatt, H., Wien, M., \& Soret, S. (2014). The environmental cost of protein food choices. Public Health Nutr, 18, 1-7.

Sachs, J. D. (2004). Sustainable development. Science, 304, 649. https://doi.org/10.1126/science.304.5671.649

SDSN. (2017). SDGs Index and Dashboard Report 2017. New York. Retrieved from http://unsdsn.org/resources/publications/sdg-index-and-dashboards-report-2017/

Serra-Majem, L., \& Ortiz-Andrellucchi, A. (2018) The Mediterranean diet as an example of food and nutrition sustainability: a multidisciplinary approach. Nutr Hosp, 12(35), 96-101.

Sofi, F., Abbate, R., Gensini, G. F., \& Casini, A. (2010) Accruing evidence on benefits of adherence to the Mediterranean diet on health: an updated systematic review and meta-analysis. Am J Clin Nutr, 92(5), 1189-96. https://doi.org/10.3945/ajen.2010.29673

Sofi, F., Macchi, C., Abbate, R., Gensini, G. F., \& Casini, A. (2014). Mediterranean diet and health status: an updated meta-analysis and a proposal for a literature-based adherence score. Public Health Nutr, 17(12), 2769-82. https://doi.org/10.1017/S1368980013003169

Tarsitano, E. (2006). Interaction between the environment and animals in urban settings: Integrated and $\begin{array}{llll}\text { Participatory Planning. } & \text { Environmental }\end{array}$ https://doi.org/10.1007/s00267-005-0148-8

Tarsitano, E., \& Calvano, G. (2018). The mediterranean way: food, tradition, innovation and sustainability. First Forum BPW Adrionnet. Commercial and Industrial Chamber of Commerce, 19th, October 2018_Athens, Greece.

Tilman, D., \& Clark, M. (2014). Global diets link environmental sustainability and human health. Nature, 515(7528), 518-22. https://doi.org/10.1038/nature13959

UN. (2017). Habitat III - New Urban Agenda. Retrieved from $\mathrm{http} / / /$ habitat3.org/wp-content/uploads/NUA-English.pdf

UN. (2018). Towards a Global Pact for the Environment. Resolution adopted by General Assembly on $10^{\text {th }}$ May 2018. New York. Retrieved from http://www.un.org/en/ga/search/view_doc.asp?symbol=A/RES/72/277

UNEP. (2010). Assessing the Environmental Impacts of Consumption and Production: Priority Products and Materials. In Hertwich E. et al. (Eds.), A Report of the Working Group on the Environmental Impacts of Products and Materials to the International Panel for Sustainable Resource Management. Retrieved from http://www.unep.fr/shared/publications/pdf/dtix1262xpa-priorityproductsandmaterials_report.pdf

Vulcano, G., \& Ciccarese, L. (2017). Spreco alimentare: un approccio sistemico per la prevenzione e la riduzione strutturali - Rapporto di sintesi. Rapporti 267/2017 ISPRA, Rome. Retrieved from http://www.isprambiente.gov.it/files2017/pubblicazioni/rapporto/R_267_17_Sprecoalimentare_sintesi.pdf

Wackernagel, M., \& Rees, W. E. (1996). Our Ecological Footprint: Reducing Human Impact on the Earth. New Society Publishers, Gabriola Island, BC.

Wackernagel, M., Schulz, N. B., Deumling, D., Linares, A. C., Jenkins, M., Kapos, V., ... Randers, J. (2002). Tracking the ecological overshoot of the human economy. Proceedings of the National Academy of Sciences, 99, 9266-9271. https://doi.org/10.1073/pnas.142033699

\section{Copyrights}

Copyright for this article is retained by the author(s), with first publication rights granted to the journal.

This is an open-access article distributed under the terms and conditions of the Creative Commons Attribution license (http://creativecommons.org/licenses/by/4.0/). 